\title{
Impact of public investment on the quality of human capital
}

\author{
I. V. Makarycheva, and G. A. Shishkanova \\ Lobachevsky State University of Nizhny Novgorod (UNN) 23 Prospekt Gagarina, 603022 Nizhny \\ Novgorod, Russia
}

\begin{abstract}
The article discusses the importance of the problem of human capital formation. Human capital is a multifaceted concept that gives the greatest return in a modern economy. It is measurable. Since 1990, the World Bank has published annual reports on its dynamics, having developed a special index called the Human Development Index. In 1990, when the index was measured for the first time, the Russian Federation was in 49th place in the ranking, but subsequently dropped to 65 . Last year we were able to move up to 41 st place. The authors trace the dynamics of government investment in human capital and the final result, which is reflected in places in the world ranking. In the nineties of the twentieth century, the Russian Federation was in a deep crisis, investments in human capital were negative, so the place in the HDI rating dropped. Currently, a number of government programs aimed at the development of human capital are being implemented, and they are paying off.
\end{abstract}

\section{Introduction}

Sustainable development of society is impossible without sustainable development of its members. The creation of a harmoniously developed personality is a long-term process that requires a fairly large amount of various resources, both moral and material. Back in the 19th century, Anton Pavlovich Chekhov wrote "Everything should be beautiful in a person: face, clothes, soul, and thoughts" [1]. In the modern world, Chekhov's ideas have been embodied in the concept of human capital. This multifaceted term includes education, health, work and creative skills, the opportunity to realize oneself. Today, when environmental problems are acute on the agenda, and the advanced countries of the world are preparing for the leap from an industrial way of life to a post-industrial way of life, it is the human capital resource that is becoming the most important and key. Unlike natural resources, the human capital resource is inexhaustible, renewable and gives a constant high return. The states that spend money on investments in human capital will certainly overtake in development those who saved on this in the long term, even if they have a large supply of resources of a different kind.

Human capital is measurable. In 1990, the Pakistani economist Mahbub ul-Haq developed a methodology for assessing it and since then the World Bank has annually published country rankings pursuant to the Human Development Index (HDI), which allows to make various international comparisons. In 2010, some changes were made to the methodology, but the idea remained approximately the same: this is the amount of human capital that a child born today may accumulate by the time of his eighteenth birthday [2]. The 
average life expectancy, the opportunity and accessibility of education for children and adults, inequality and poverty are considered, and after 2010 the index still includes gender inequality and the index of multidimensional poverty. The definition of human development, which was formulated by the World Bank, is as follows: "Human development is a process of expanding the freedom of people to live long, healthy and creative lives, to achieve other goals that, in their opinion, have value; actively participate in ensuring fairness and sustainable development on the planet" [3].

Since the beginning of the publication of the index falls on the post-Soviet times, it is quite problematic to draw an analogy with the USSR. In the nineties and zero, our rating was not very brilliant for a developed country. But in 2020 we made a leap, jumping from 54th to 41 st place [4]. It seems that this is due to the cumulative effect of numerous government programs that have begun to be implemented recently, namely from the beginning of the second decade of the 21 st century. In our study, we will try to identify the relationship between state investments in various areas of the social sphere and the quality of life of the population of our country.

\section{Materials and methods}

In our research, we will use mainly statistical methods, methods of analogy and extrapolation. The materials will be official data from Rosstat, data from the World Bank and official data from the portal of the State Programs of the Russian Federation.

\section{Results and discussion}

As we defined above, human capital is a multifaceted category that includes health, education, the ability to be productive, the level of satisfaction with life conditions (mental health), and much more. In turn, each of these positions consists of a number of components. Thus, for instance, the health of a nation is made up of both the health care system itself, the availability of high-quality medical services for the general population, and the involvement of citizens in a "healthy lifestyle", the availability of physical education and sports, and disease prevention. "Mental health" is generally a complex concept, which is influenced by so many factors, both directly and indirectly, that it is very difficult to enumerate them completely. Therefore, investments in any social projects, of course, represent investments in human capital, in one or another of its components.

The USSR, for all its shortcomings, invested quite seriously in human capital. For 70 years, he managed to turn a semi-illiterate peasant country into one of the superpowers, one of the "poles of power", send a man into space, achieve $99.7 \%$ literacy, and a high average life expectancy.

The collapse of the Soviet Union took a heavy toll on the social sphere. Formally, the basic values: free education and medical care remained unchanged, but the quality of services provided significantly decreased. The growth in the salaries of doctors and teachers lagged significantly behind inflation, and in general, the real income of the population dropped significantly (Fig. 1). The inflation rate was such that it sharply depreciated the savings of citizens (Table 1), the indexation of wages did not keep pace with the inflation rate, a significant number of the population found itself below the poverty line, and crime increased.

Table 1. Inflation rate in $\%$ on an annualized basis [7].

\begin{tabular}{|l|l|l|l|l|l|l|l|l|l|}
\hline 1991 & 1992 & 1993 & 1994 & 1995 & 1996 & 1997 & 1998 & 1999 & 2000 \\
\hline 160.4 & 2508.85 & 839.87 & 215.02 & 131.33 & 21.81 & 11.03 & 84.44 & 36656 & 20.2 \\
\hline
\end{tabular}




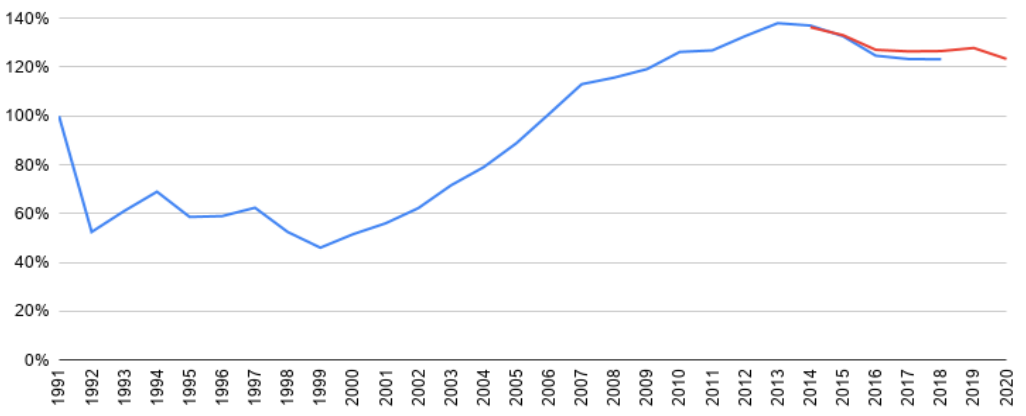

Fig. 1. Real disposable income of the population of the Russian Federation in\% to the level of 1991 [6].

Of course, this could not but affect the deterioration of the quality of life and the decline in the cost of national capital. First of all, the indicators of average life expectancy worsened. The most suffering citizens were older people living on fixed incomes. In addition, the number of suicides has increased. This led to the fact that in four years from the beginning of the nineties, the average life expectancy fell by five years, and over the next 15 years it could not win back the initial fall (Table 2).

Table 2. Average life expectancy [4].

\begin{tabular}{|c|c|c|c|}
\hline \multirow{2}{*}{ Years } & \multicolumn{3}{|c|}{ Total } \\
\cline { 2 - 4 } & Both sexes & Men & Women \\
\hline 1990 & 69.19 & 63.73 & 74.30 \\
\hline 1993 & 65.14 & 58.97 & 71.88 \\
\hline 1994 & 63.98 & 57.59 & 71.18 \\
\hline 1995 & 64.52 & 58.12 & 71.59 \\
\hline 2000 & 65.34 & 59.03 & 72.26 \\
\hline 2006 & 66.69 & 60.43 & 73.34 \\
\hline 2009 & 68.78 & 62.87 & 74.79 \\
\hline
\end{tabular}

Even infant mortality, an indicator that has been steadily declining for a long time, saw a surge in growth in 1995 (Fig. 2). It is not surprising that the Russian Federation was one of the few countries in the world that, over the decade since the beginning of HDI measurement (1990-2000), reduced the index from 0.734 to 0.720 , dropping from 49th to 65th place in the world ranking [9].

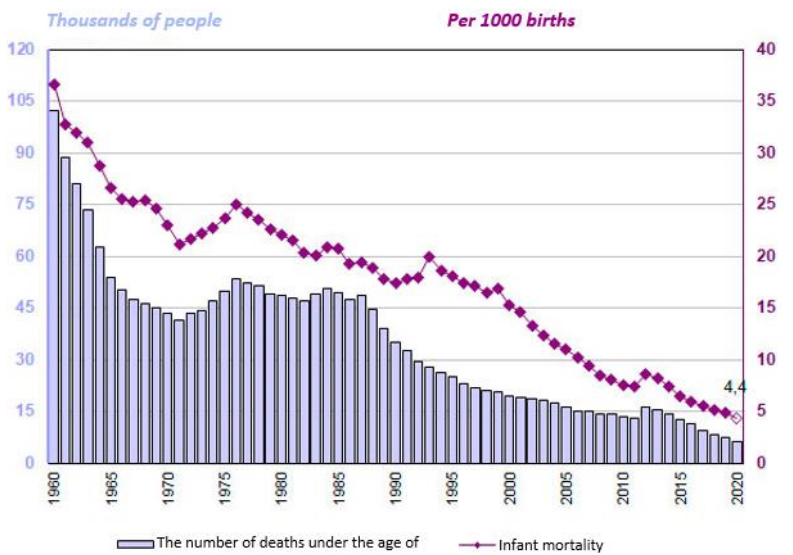

Fig. 2. The number of deaths under the age of 1 year (thousand people) and the infant mortality rate (deaths under 1 year of age per 1 live birth), 1960-2020 [8]. 
The government's inattention to the social sphere is largely due to the banal budget deficit. The crisis of the change in social order hit all branches of social production very hard. As may be seen from Table 3, the overall drop in GDP over the ten "post-revolutionary" years was $44 \%$, and some anti-records were set by industrial production $(-57 \%)$ and manufacturing $(-64 \%)$. Enterprises were closed en masse, people lost their jobs, investments were practically absent.

Table 3. Dynamics of key indicators of Russia, growth over the period,\% [9].

\begin{tabular}{|l|c|c|c|}
\hline & $1989-1998$ & $1998-2008$ & $2008-2016$ \\
\hline GDP & -44 & 95 & 3 \\
\hline Investment in MC & -79 & 229 & -4 \\
\hline Extractive industry & -35 & 57 & 9 \\
\hline Manufacturing industry & -64 & 104 & 3 \\
\hline Electric power, gas and water & -24 & 19 & -2 \\
\hline Retails & 4 & 161 & 5 \\
\hline Food sales & -4 & 121 & -2 \\
\hline Non-food sales & 9 & 202 & 12 \\
\hline Sales of the organizations (shops) & -17 & 207 & 13 \\
\hline Industrial production & -57 & 77 & 4 \\
\hline
\end{tabular}

However, the crisis does not last forever, and gradually our country began to recover. The 1998 currency crisis helped a lot in this, as a result of which, although inflation increased (Table 8), import substitution became more active. As a result, over the decade of 1998-2008, the manufacturing industry showed $104 \%$ growth. GDP has grown as well. Taxes have increased. Increase in prices for oil was steady. The government had obtained money.

Instead of the previous policy of solving urgent problems, the government now has the opportunity to pursue a strategic policy of harmonious development of the country on the basis of balanced budgets allocated for certain state programs. Of course, state programs existed before that, but only after 2010 they began to take on a balanced form and actually work. Currently, $70 \%$ of the state budget is spent through state programs in various directions [13].

Currently, 46 state programs are being implemented in our country in five main areas:

1) Innovative development and modernization of the economy

2) Balanced regional development

3) An effective state

4) New quality of life

5) Ensuring national security

From the HDI point of view, the most interesting is the direction "New quality of life". Within its framework, eight programs are being implemented:

1) Social support of the population

2) Assistance of employment of the population

3) Development of physical culture and sport

4) Culture development

5) Development of the state national policy

6) Available environment

7) Environmental protection

8) Provision of affordable and comfortable housing and utilities

All these programs are undoubtedly important and contribute to the harmonious development of the state. But if we talk from the point of view of the place of the Russian Federation in the HDI rating, the most interesting is the program of social support for the population. Within its framework, a demographic policy is being implemented, support for pensioners and low-income citizens. The state program "effective state" is also important, 
within the framework of which the development of health care is carried out. Most of the programs started operating in 2012-2013, and during this time a lot of money was spent and good results were obtained. But we are primarily interested in indicators that affect the HDI.

The average life expectancy is slowly, not steadily increasing (Table 4). This is achieved through better living conditions, an increase in real disposable income (Fig. 1), and enhanced medical care.

Table 4. Life expectancy at birth [4].

\begin{tabular}{|c|c|c|c|}
\hline \multirow{2}{*}{ Years } & \multicolumn{3}{|c|}{ All population } \\
\cline { 2 - 4 } & total & men & women \\
\hline 2012 & 70.24 & 64.56 & 75.86 \\
\hline 2013 & 70.76 & 65.13 & 76.30 \\
\hline $2014^{2)}$ & 70.93 & 65.29 & 76.47 \\
\hline 2015 & 71.39 & 65.92 & 76.71 \\
\hline 2016 & 71.87 & 66.50 & 77.06 \\
\hline 2017 & 72.70 & 67.51 & 77.64 \\
\hline 2018 & 72.91 & 67.75 & 77.82 \\
\hline 2019 & 73.34 & 68.24 & 78.17 \\
\hline
\end{tabular}

Maternal and child health indicators have also enhanced significantly. Both infant mortality decreased (Fig. 2) and the overall health indicators of newborns (Table 5)

Table 5. The number of newborns born sick and got sick [5].

\begin{tabular}{|l|c|c|c|c|c|c|c|}
\hline & 2012 & 2014 & 2015 & 2016 & 2017 & 2018 & 2019 \\
\hline $\begin{array}{l}\text { Health status of } \\
\text { newborns - the } \\
\text { number of newborns } \\
\text { born sick and sick, } \\
\text { people }\end{array}$ & & & & & & \\
\hline total & 643525 & 637518 & 614063 & 597155 & 534556 & 502993 & 461586 \\
\hline including: & 6362 & 6704 & 6650 & 6645 & 6101 & 6076 & 5827 \\
\hline $\begin{array}{l}\text { with a body weight of } \\
500-999 \text { g. }\end{array}$ & 630814 & 607413 & 590510 & 528455 & 496917 & 455759 \\
\hline $\begin{array}{l}\text { with a body weight of } \\
1000 \text { g and more }\end{array}$ & 637163 & 630814 & & & & \\
\hline
\end{tabular}

Within the framework of the state program "Development of Education" only in 20192020, the following key indicators were achieved: 5000 "growth points" were opened, where children from rural areas and small towns may master advanced educational programs, in 2391 schools in rural areas and small towns overhaul and renovation of gyms was carried out, more than 140 thousand new training places were created, etc. [14].

The government is not going to be satisfied with what has already been achieved. Thus, on the website of government programs, we managed to find such a schedule for financing various directions (Fig. 3). Unfortunately, the allocated money is not always used (this is a topic for a separate article), but the plan, in any case, is optimistic. Of course, 2020 is already the past period, but there were no delays in budget payments in the past period. 


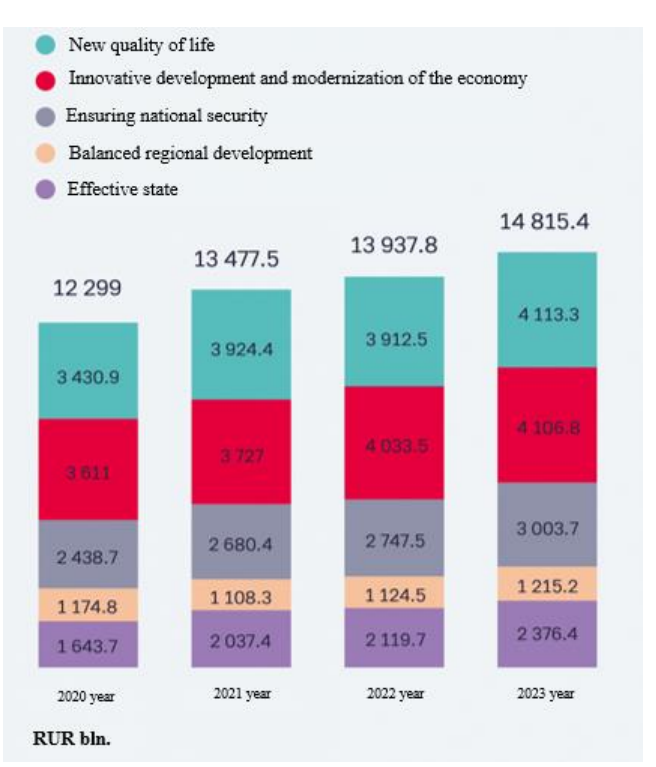

Fig. 3. Plan for expenditures for the implementation of state programs [13].

\section{Conclusion}

Human capital is one of the most important resources on the planet and the main asset of any state. But, like any resource, it is not given for free. In order for the state to be able to receive high-quality human capital (and subsequently a high return on it), it must create conditions for its favorable formation. It is required to invest in human capital continuously. The Soviet Union created a fairly large reserve in terms of human capital, in 1990, when the HDI was just beginning to be calculated, Russia was in 49th place in the world, but it was worth stopping investments, as literally in 10 years we slipped to 65 . As soon as the state resumed investments, and, (albeit not quickly), we were not only able to restore the former level, but also to enhance it, reaching 41 st place. If the social policy of our state does not deteriorate, then our country has every chance of further improving the HDI. Herewith, one needs to understand that in itself a place in the rating does not mean anything, It is just a figure that reflects some indicators. What is really important is the overall result that the enhancement of human capital has on the national wealth of the country. The more educated and healthier the population is, the greater the return on investment for the state. The World Bank website would find an excellent illustration of the government's contribution to human capital formation (Figure 4). The state - roots. All its activities lead either to the prosperity of the crown, or to its drying. We hope that the crown called "Russia" will only be more magnificent and stronger. 


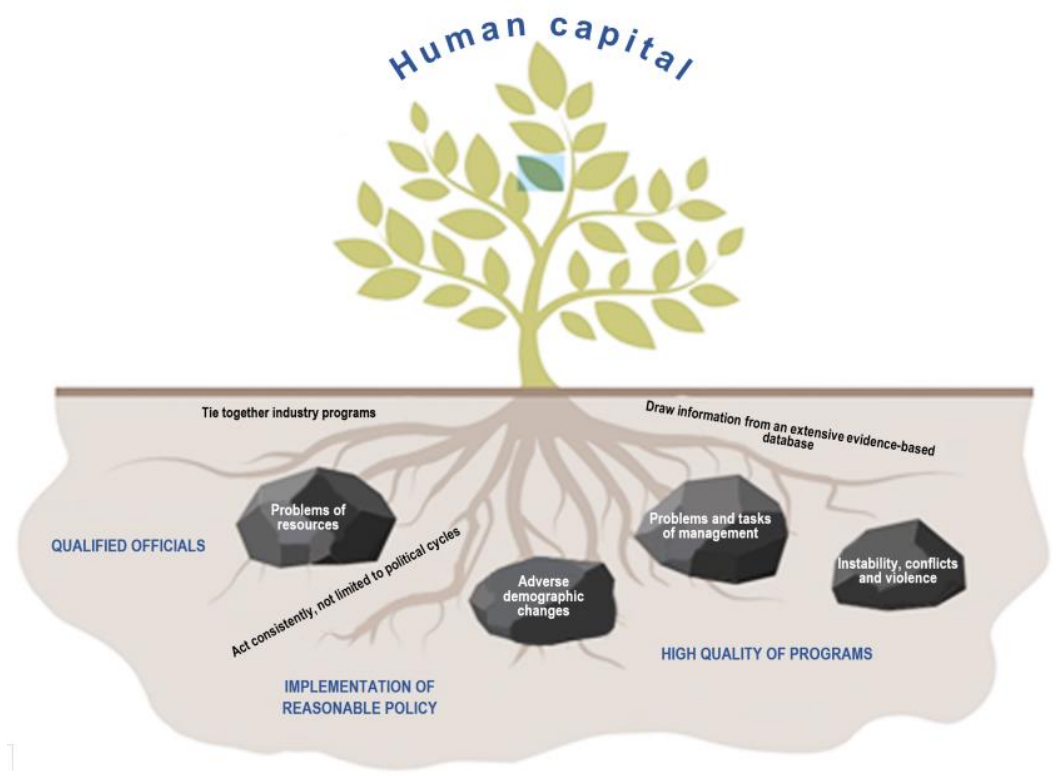

Fig. 4. Forming of the human capital [12].

\section{References}

1. A. P. Chekhov. Complete works and letters in 30 volumes. Compositions, 13 (1986)

2. International Bank for Reconstruction and Development/World Bank, Project Development Human Of Capital (2018) https://openknowledge.worldbank.org

3. Human Capital Project (2020) https://www.vsemirnyjbank.org

4. Federal State Statistics Service, Demographics, https://rosstat.gov.ru

5. Life expectancy at birth (2019) https://data.worldbank.org

6. Standard of living, Standard of living, https://rosstat.gov.ru/folder/13397

7. The level of-inflation, https://xn----ctbjnaatncev9av3a8f8b.xn--p1ai

8. Demographic results of the first half of 2020 in Russia (part II), http://www.demoscope.ru

9. L. M. Grigoriev. Features of development of the human capital in territorial subjects of the Russian Federation the RF Government Analytical Center (2019) https://ac.gov.ru

10. A. A. Zudina, The roads cleading youth in NEET: case of Russia, 22(2) (2018) https://elibrary.ru

11. I. V. Makarycheva, G. A. Shishkanova, I. A. Kulagova, New population policy and its influence on the national human capital, https://elibrary.ru

12. T. L. Sudova, State investments into the human capital (2017) https://cyberleninka.ru

13. Ministry of Economic Development of the Russian Federation, Portal Of State Programs Of The Russian Federation, https://programs.gov.ru/

14. Ministry of Education of the Russian Federation, Key Results Of The National Project "Education», https://edu.gov.ru/national-project/results/

15. International Bank for Reconstruction and Development/World Bank, Project Development Human Of Capital (2018) https://openknowledge.worldbank.org 